\title{
Side Effects of Transplant Immunosuppressive Therapy in Post Renal Transplant Recipients, Mazandaran, Northern Iran
}

\author{
Abazar Akbarzadeh Pasha, ${ }^{1}$ Shayan Alijanpour,, ${ }^{2,}$ Soraya Khafri, ${ }^{3}$ Hoshmand Basim, ${ }^{4}$ and Mehran
}

\author{
Afshang $^{5}$ \\ ${ }^{1}$ Department of Urology, Babol University of Medical Sciences, Babol, Iran \\ ${ }^{2}$ Emergency Medical Service Center, Babol University of Medical Sciences, Babol, Iran \\ ${ }^{3}$ Department of Social Medicine, Babol University of Medical Sciences, Babol, Iran \\ ${ }^{4}$ Student Research Committee, Babol University of Medical Sciences, Babol, Iran \\ ${ }^{5}$ Babol University of Medical Sciences, Babol, Iran \\ "Corresponding author: Shayan Alijanpour, Emergency Medical Service Center, Babol University of Medical Sciences, Babol, Iran. Tel: +98-9117912187, E-mail: \\ alijanpour.sh@live.com
}

Received 2016 April 27; Accepted 2017 April 22.

\begin{abstract}
Background: Post-kidney transplant survival relies on patient adherence to the intake of immunosuppressive medication. This study was performed to investigate complications associated with immunosuppressive therapy in renal transplantation.

Methods: This cross-sectional study was conducted on 188 transplanted patients in Shahid Beheshti hospital of Babol in 2013. Check list and demographic questionnaire for data collecting were used. Then the data using were analyzed in SPSS.18 software by using chi-square test.

Results: A total of 188 transplanted patients, 115 (61.2\%) was male and mean age was $12.9 \pm 42.9$ years. 181(96.3\%) of the subjects had at least one complication. The most common complication in 142 cases (75.5\%) was "excessive hair growth" and after this complication "increased blood sugar" had higher frequency and 119 (63.3\%) had this complication. Severe form of gingival overgrowth in women was significantly that more than men $(22(30.1), 14(12.2), \mathrm{P}=0.004)$, and the other side effect was not significant difference between men and women or different age groups $(\mathrm{P}>0.05)$

Conclusions: Finding show that nearly all transplanted recipients suffered from one complication which need to recognize, control and treatment. It suggested that period visiting for early diagnosis and education to patient was recommend.
\end{abstract}

Keywords: Renal Transplantation, Drug Complications, Immunosuppressive Therapy

\section{Background}

Renal transplantation is choice treatment for most patients with end-stage renal disease [1]. Over the past decade, significant progress has been made in improving graft and patient survival within renal transplantation [2]. In our center 1 and 3-year renal transplant survival rates were $98.8 \%$ and $97.3 \%$, respectively on other hand 1 and 3year patient's survival was $96.6 \%$ and 93.1\% [1]. Renal transplant survival was thought to be due to combinations of immunosuppressive drugs with different mechanisms of action [3]. Wide range of immunosuppressive drugs is available to prevent acute rejection after renal transplantation [4] include cyclosporine, tacrolimus, mycophenolate mofetil, sirolimus, anti-interleukin-2 receptor antibodies, anti-lymphocyte antibodies and everolimus [5-8]. However, there was short- and long-term toxicities associated with these immunosuppressive drugs. Such adverse effects can range from the mild through to the severe. Mild adverse events such as nausea, discomfort, appetite loss and severe events include: severe diarrhea, nephrotoxicity, hyperlipidemia, diabetes. These complications decrease patients' quality of life [9-11]. Furthermore, comorbidities linked to immunosuppressant regimens are a major cause of dosage reductions or treatment cessations, which can have a unfavorable effect on efficacy and survival rates [12, 13]. These adverse effects are not similar in different studies, so the aim of this study was to determine the common complications of medication in renal recipient after renal transplantation.

\section{Methods}

This cross-sectional study was conducted with census method on renal receptions who transplanted since 2010 to 2012 in the Shahid Beheshti hospital (Renal transplant center of Mazandaran, Northern Iran). Patients were recalled with a phone call. Of 250 transplanted patients, 65 Patients with history of renal graft rejection and not satisfaction in participation in study were excluded from this study. Data was collected by the check Lists 
and demographics questionnaire. Information was gathered by presence interviews. Check list was included: 11 important symptoms (excessive hair growth, hair loss, headaches, tremors, gingival overgrowth, diarrhea, acne, trouble sleeping, increased blood sugar, weight gain, fatigue), respectively. The response to these questions was including no complication, moderate and severe complication. For every symptom severity was defined. Weight gain from 3 to $6 \mathrm{~kg}$ was considered low and more than 7 $\mathrm{kg}$ considered excessive. Fasting blood sugar level between 100 and $125 \mathrm{mg} / \mathrm{dL}$ was considered low and FBS more than $126 \mathrm{mg} / \mathrm{dL}$ considered severe complication. Excessive hair growth in hand was defined mild and in ear and nose defined severe. Gingival overgrowth was severe in patients that returned to specialist dentist and without too much trouble for the patient was considered mild. Persistent acne was defined severe and in some time defined mild. Fatigue without affecting on individual and social activities was considered, low and otherwise severe. Permanent trouble sleeping was considered severe and otherwise mild. The most common medication is a mixture of mycophenolate ( 2 - 4 gr/day), prednisolone ( $5-7 / 5 \mathrm{mg} /$ day) and ciclosporin (12-15 mg/kg/day) [14].

Data were analyzed by SPSS 18 software and chi square test and $\mathrm{P}<0.05$ was considered statistically significant.

\section{Results}

A total of 188 transplanted patients, 115 (61.2\%) was male and 73 (38.8\%) was female. Mean age was $12.9 \pm 42.9$ years, range 13 to 73 years. 181 cases (96.3\%) had at least one complication. The most common complication in 142 cases (75.5\%) were "excessive hair growth" and after this complication "increased blood sugar" had higher frequency and 119 (63.3\%) had this complication (Table 1).

Age and gender distribution of severe complications was shown in Table 2. Severe form of gingival overgrowth in women was significantly more than men, and the other side was not significant difference between men and women or different age groups.

\section{Discussion}

Currently, renal transplantation is the best treatment for ESRD despite the advantages that can be associated with complications. The side effects of drugs that suppress the immune system are resulting in failure to compliance of these drugs and affects in different aspects of life, finally leading to reduced quality of life [14]. Therefore, this study has been performed to investigate the Side effects of transplant immunosuppressive therapy after renal transplantation procedures. In Radwan study showed that influential
Table 1. Distribution of Common Complications of Medication in Renal Recipient After Renal Transplantation ${ }^{\mathrm{a}}$

\begin{tabular}{|lcc|}
\hline Variable & \multicolumn{2}{c}{ Complication } \\
\cline { 2 - 3 } & \multicolumn{1}{c}{ Mild } & Severe \\
\hline Excessive hair growth & $86(45.7)$ & $56(29.8)$ \\
\hline Weight gain & $36(19.1)$ & $11(5.9)$ \\
\hline Fatigue & $70(37.2)$ & $12(6.4)$ \\
\hline Tremors & $89(47.3)$ & $16(8.5)$ \\
\hline Headaches & $23(12.2)$ & $7(3.7)$ \\
\hline Acne & $39(20.7)$ & $2(2.1)$ \\
\hline Diarrhea & $57(30.3)$ & $10(5.3)$ \\
\hline Trouble sleeping & $51(27.1)$ & $14(7.4)$ \\
\hline Hair loss & $34(18.1)$ & $20(10.6)$ \\
\hline Gingival overgrowth & $73(38.3)$ & $36(19.1)$ \\
\hline Increased blood sugar & $95(50.5)$ & $24(12.8)$ \\
\hline
\end{tabular}

${ }^{\mathrm{a}}$ Values are expressed as No. (\%).

factors on gingival overgrowth in renal transplant patients is suppressant drugs such as cyclosporine [15] the results of our study showed that 109 patients (57.9\%) had gingival overgrowth. The prevalence of gingival overgrowth by cyclosporine increased $30 \%$ of patients that receiving this drug in some research [16-18] However, in Al-Mohaya study this rate was $74.1 \%[19]$. The difference in the prevalence of this complication may be the post transplantation period that seems to be inversely proportional to the prevalence of this disorder.

The prevalence of diabetes before and after transplantation was $12.8 \%$. In the Poormand study diabetes complications were reported in $14 \%$ and Soleimani study $21 \%$ of patients, the onset of diabetes after transplantation was seen $[20,21]$. That in line with this study. The post transplantation period could affect this prevalence. In Kasiske study prevalence of Diabetes after three months from the time of transplantation was $9.1 \%$ but this value after three years later was $24 \%$ [22] that was shown direct comparison between post transplantation period and this condition. In Laupacis study concluded that excessive hair growth, acne and weight gain increased with post transplantation period. Our results also showed that over three years, 75.5\% of patients had excessive hair growth that was in line with this study.

Our results indicate that 65 cases (34.5\%) had trouble sleeping and sleep problems that was nearly to Silva study (36\%) in Brazil [23]. It is expected that a successful kidney transplant in patients with unusual problems corrected this problem, but studies show that sleep disorders after 
Table 2. Age and Gender Distribution of Severe Complications in Renal Transplanted Patients

\begin{tabular}{|c|c|c|c|c|c|c|c|}
\hline \multirow[t]{2}{*}{ Variable } & \multicolumn{3}{|c|}{ Sex } & \multicolumn{4}{|c|}{ Age Group } \\
\hline & Male & Female & Pvalue & $<45$ & $45-60$ & $\geq 6 \mathbf{6 1}$ & Pvalue \\
\hline Excessive hair growth & $29(25.2)$ & $27(37)$ & 0.102 & $34(32.1)$ & $15(23.8)$ & $6(35.3)$ & 0.451 \\
\hline Weight gain & $5(4.3)$ & $6(8.2)$ & 0.343 & $8(7.5)$ & $2(3.2)$ & $1(5.9)$ & 0.413 \\
\hline Fatigue & $4(3.5)$ & $8(11)$ & 0.063 & $10(9.4)$ & $2(3.2)$ & - & 0.054 \\
\hline Tremors & $11(9.6)$ & $5(6.8)$ & 0.6 & $13(12.3)$ & $2(3.2)$ & $1(5.9)$ & 0.115 \\
\hline Headaches & $3(2.6)$ & $4(5.5)$ & 0.433 & $5(4.7)$ & $1(1.6)$ & $1(5.9)$ & 0.704 \\
\hline Acne & $1(0.9)$ & $3(4.1)$ & 0.301 & $2(1.9)$ & $1(1.6)$ & $1(5.9)$ & 0.483 \\
\hline Diarrhea & $5(4.3)$ & $5(6.8)$ & 0.514 & $8(7.5)$ & $1(1.6)$ & - & 0.056 \\
\hline Trouble sleeping & $5(4.3)$ & $9(12.3)$ & 0.05 & $9(8.5)$ & $3(4.8)$ & $2(11.8)$ & 0.889 \\
\hline Hair loss & $10(8.7)$ & $10(13.7)$ & 0.334 & $7(6.6)$ & $9(14.3)$ & $3(17.6)$ & 0.16 \\
\hline Gingival overgrowth & $14(12.2)$ & $22(30.1)$ & 0.004 & $24(22.6)$ & $9(14.3)$ & $3(17.6)$ & 0.406 \\
\hline Increased blood sugar & $16(13.9)$ & $8(11)$ & 0.657 & $12(11.3)$ & $8(12.7)$ & $4(23.5)$ & 0.378 \\
\hline
\end{tabular}

transplantation was also identified [24,25].

Gastrointestinal complications after transplantation are seen in $10 \%$ of cases [26]. One of the immunosuppressant's agents is diarrhea and in our study, 67 patients (35.6\%) had diarrhea. However, diarrhea can also occur for other reasons such as infection [27]. Frothy one patients (22.8\%) had acne while in Euvrard study 5.5\% had acne [28]. Higher rates can be attributed to low awareness of the condition.

Limitation of this work was there was not standard measurement in renal immunosuppressive drug complication that leads to could not able to compare different study together.

Review the most common Side effects of transplant immunosuppressive therapy after renal transplantation was first performed in this study and different knowledge of patients transplanted had an impact on our results. The results of our study showed that after three years of transplantation, nearly all patients' transplanted suffering from at least one side effect. All these effects need to identify, control and treatment. Examined periodically for faster detection and patient education is recommended to see if any side effects. A complete study with large scale is recommended for prevalence of symptoms and treatment, and control.

\section{Acknowledgments}

We thank from chancellor for research and technology of Babol University of Medical Sciences for financial support (Proposal Number: 1702) and student research committee for their cooperation.

\section{Footnotes}

Authors' Contribution: Abazar Akbarzadeh Pasha, Shayan Alijanpour, participated in the organization, writing, and final editing of this paper and approved the final version. Soraya Khafri participated in the writing and editing of this paper and approved the final version. Hoshmand Basim, Mehran Afshang participated in the writing of this paper and approved the final version.

Conflict of Interests: The authors declare that there is no conflict of interests regarding the publication of this paper.

Funding/Support: Babol University of Medical Sciences.

\section{References}

1. Akbarzadeh Pasha A, Sorkhi H, Razzaghi E, Oliaei F, Gholizadeh Pasha AR, Alizadeh Navaei R, et al. Outcome of 200 kidney transplantation in kidney transplant center of Shahid Beheshti hospital in Babol (Iran) [In persian]. J Babol Univ Med Sci. 2012;14(2):82-8.

2. Davies NM, Grinyo J, Heading R, Maes B, Meier-Kriesche HU, Oellerich M. Gastrointestinal side effects of mycophenolic acid in renal transplant patients: a reappraisal. Nephrol Dial Transplant. 2007;22(9):2440-8. doi: 10.1093/ndt/gfm308. [PubMed: 17557774].

3. Kaufman DB, Shapiro R, Lucey MR, Cherikh WS, T. Bustami R , Dyke DB. Immunosuppression: practice and trends. Am J Transplant. 2004;4 Suppl 9:38-53. doi: 10.1111/j.1600-6135.2004.00397.x. [PubMed: 15113354].

4. Hódi Z, Szenohradszky P, Marofka F, Szederkényi E. Gastrointestinal side effects of mycophenolate mofetil compared to mycophenolic acid in renal transplant patients. Z Gastroenterol. 2006;44(05):43-4. doi: $10.1055 / \mathrm{s}-2006-943410$.

5. Kahan BD. Efficacy of sirolimus compared with azathioprine for reduction of acute renal allograft rejection: a randomised multicentre study. The Rapamune US Study Group. Lancet. 2000;356(9225):194202. doi: 10.1016/S0140-6736(00)02480-6. [PubMed:10963197]. 
6. Pirsch JD, Miller J, Deierhoi MH, Vincenti F, Filo RS. A comparison of tacrolimus (FK506) and cyclosporine for immunosuppression after cadaveric renal transplantation. FK506 Kidney Transplant Study Group. Transplantation. 1997;63(7):977-83. doi: 10.1097/00007890199704150-00013. [PubMed: 9112351].

7. Neumayer HH, Farber L, Haller P, Kohnen R, Maibucher A, Schuster A, et al. Substitution of conventional cyclosporin with a new microemulsion formulation in renal transplant patients: results after 1 year. Nephrol Dial Transplant. 1996;11(1):165-72. doi:10.1093/oxfordjournals.ndt.a027035. [PubMed: 8649628].

8. Vincenti F, Kirkman R, Light S, Bumgardner G, Pescovitz M, Halloran $\mathrm{P}$, et al. Interleukin-2-receptor blockade with daclizumab to prevent acute rejection in renal transplantation. Daclizumab Triple Therapy Study Group. N Engl J Med. 1998;338(3):161-5. doi: 10.1056/NEJM199801153380304. [PubMed: 9428817].

9. Boots JM, Christiaans MH, van Hooff JP. Effect of immunosuppressive agents on long-term survival of renal transplant recipients: focus on the cardiovascular risk. Drugs. 2004;64(18):2047-73. doi: 10.2165/00003495-200464180-00004. [PubMed: 15341497].

10. Lo A, Alloway RR. Strategies to reduce toxicities and improve outcomes in renal transplant recipients. Pharmacotherapy. 2002;22(3):316-28. doi: 10.1592/phco.22.5.316.33198. [PubMed: 11898890].

11. Gentil MA, Lopez M, Gonzalez-Roncero F, Cantarell C, Marco J. Cost of renal transplant maintenance immunosuppression: effect of control of vascular risk factors. Transplant Proc. 2005;37(3):1464-5. doi: 10.1016/j.transproceed.2005.02.011. [PubMed: 15866640].

12. Pelletier RP, Akin B, Henry ML, Bumgardner GL, Elkhammas EA, Rajab A, et al. The impact of mycophenolate mofetil dosing patterns on clinical outcome after renal transplantation. Clin Transplant. 2003;17(3):200-5. doi: 10.1034/j.1399-0012.2003.00026.x. [PubMed: 12780668].

13. Knoll GA, MacDonald I, Khan A, Van Walraven C. Mycophenolate mofetil dose reduction and the risk of acute rejection after renal transplantation. J Am Soc Nephrol. 2003;14(9):2381-6. doi: 10.1097/01.ASN.0000079616.71891.F5. [PubMed:12937317].

14. Azmandiyan J, Sohravardi SM, Fazeli F, Etminan A, Sarveram A, Afzal F. The efficacy of amlodipine and diltiazem in cyclosporine dose adjustment with respect to trough and 2-hour concentrations in kidney transplant patients [In Persian].J Kerman Univ Med Sci. 2009;16(3):197205.

15. Radwan-Oczko M, Boratynska M, Klinger M, Zietek M. Risk factors of gingival overgrowth in kidney transplant recipients treated with cyclosporine A. Ann Transplant. 2003;8(4):57-62. [PubMed: 15171009].

16. Hassell TM. Evidence for production of an inactive collagenase by fibroblasts from phenytoin-enlarged human gingivae. J Oral Pathol.
1982;11(4):310-7. doi: 10.1111/j.1600-0714.1982.tb00171.x. [PubMed 6286912].

17. Seymour RA, Smith DG, Rogers SR. The comparative effects of azathioprine and cyclosporin on some gingival health parameters of renal transplant patients. A longitudinal study. J Clin Periodontol. 1987;14(10):610-3. doi:10.1111/j.1600-051X.1987.tb01524.x. [PubMed: 3320101].

18. Seymour RA, Thomason JM, Nolan A. Oral lesions in organ transplant patients.J Oral Pathol Med. 1997;26(7):297-304.

19. Al-Mohaya MA, Darwazeh AM, Bin-Salih S, Al-Khudair W. Oral lesions in Saudi renal transplant patients. Saudi J Kidney Dis Transpl. 2009;20(1):20-9. [PubMed: 19112215].

20. Pourmand MR, Keshtvarz M, Soltan Dallal MM, Talebi M, Bakhtiari R Urinary tract infection in renal transplant patients in Sina University hospital [In Persian]. Tehran J Univ Med Sci. 2014;71(2):114-21.

21. Soleimani AR, Mianesaz E, Tamadon MR, Mousavi SGA. Evaluation of the relationship between diabetes mellitus and kidney transplantation [In Persian]. Feyz J Kashan Univ Med Sci. 2008;12(3):63-7.

22. Gunnarsson R, Arner P, Lundgren G, Magnusson G, Ostman J, Groth CG. Diabetes mellitus-a more-common-than-believed complication of renal transplantation. Transplant Proc. 1979;11(2):1280-1. [PubMed: 382510].

23. Silva DS, Andrade Edos S, Elias RM, David-Neto E, Nahas WC, Castro MC, et al. The perception of sleep quality in kidney transplant patients during the first year of transplantation. Clinics (Sao Paulo). 2012;67(12):1365-71. doi: 10.6061/clinics/2012(12)04. [PubMed: 23295588].

24. Rodrigue JR, Mandelbrot DA, Hanto DW, Johnson SR, Karp SJ, Pavlakis M. A cross-sectional study of fatigue and sleep quality before and after kidney transplantation. Clin Transplant. 2011;25(1):E13-21. doi 10.111/j.1399-0012.2010.01326.x. [PubMed: 20961334].

25. Kovacs AZ, Molnar MZ, Szeifert L, Ambrus C, Molnar-Varga M, Szentkiralyi A, et al. Sleep disorders, depressive symptoms and health-related quality of life-a cross-sectional comparison between kidney transplant recipients and waitlisted patients on maintenance dialysis. Nephrol Dial Transplant. 2011;26(3):1058-65. doi: 10.1093/ndt/gfq476. [PubMed: 20685829].

26. Ponticelli C, Passerini P. Gastrointestinal complications in renal transplant recipients. Transpl Int. 2005;18(6):643-50. doi:10.1111/j.1432 2277.2005.00134.x. [PubMed: 15910287].

27. Pescovitz MD, Navarro MT. Immunosuppressive therapy and posttransplantation diarrhea. Clin Transplant. 2001;15 Suppl 4:23-8. doi: 10.1111/j.1399-0012.2001.00023.x. [PubMed: 11778784].

28. Euvrard S, Kanitakis J, Cochat P, Cambazard F, Claudy A. Skin diseases in children with organ transplants. J Am Acad Dermatol. 2001;44(6):932-9. doi:10.1067/mjd.2001.113465. [PubMed: 11369903]. 